\title{
Television Betting Advertisements and The Gambling Behavior of Undergraduate University Students Aged Between 18 And 25 Years In Kiambu County Kenya
}

\author{
1*Juliet Waruguru Mwai \\ Studies, Jomo Kenyatta University of Agriculture and Technology \\ *E-mail: mwaijuliet@gmail.com \\ ${ }^{2}$ Professor Hellen Mberia \\ Lecturer, Jomo Kenyatta University of Agriculture and Technology \\ DOI: 10.29322/IJSRP.11.11.2021.p11930 \\ http://dx.doi.org/10.29322/IJSRP.11.11.2021.p11930
}

Postgraduate Student: Department of Media Technology and Applied Communication, School of Communication and Development

\begin{abstract}
Purpose: The general objective of the study is to establish the effect of television betting advertisements on the gambling behaviour of undergraduate university students aged between 18 and 25 years in Kiambu county Kenya.

Methodology: This study applied a descriptive research design. The study targeted the Public Chartered Universities that are in Kiambu County. The respondents were the undergraduate students from the School of Communications \& Development Studies (SCDS) and the school of business (students between 18 and 25 years of age, those who have mobile betting accounts and those who have gambled at least once in the past 12 months to be eligible to participate in this research). The study adopted a stratified random sampling technique to select the sample size. Since the population is indefinite, that is, more than 10000 students, the study considered a sample frame of equal number of students across the 4 strata. Thus, the sample frame included 384 students from the universities. The study used questionnaires to collect the data from the target respondents. Analysis was done by use of SPSS software (v22.0). The quantitative data was analyzed using descriptive and inferential statistics (Chi-square tests \& binary logistic regression). The results from the descriptive analysis were in form of mean, standard deviations, and frequencies as well as in percentage form. Chi-square tests were carried out (at 95\% confidence interval/0.05 significance level). Results were then presented in tables, diagrams and charts. Qualitative data were analyzed using content analysis and the results were presented in thematically.
\end{abstract}

Results: This study demonstrated that the gambling behaviour of undergraduate university students in Kenya is influenced by the television betting advertisements on the gambling behaviour of undergraduate. This has been shown by the students gambling behaviour which is validated by the number of bets they place, how frequently they bet and the money used to place the bets. As such the study has concluded irresponsible gambling behaviour which is attributed to high frequency of television betting advertisements. In addition, the study concludes that brand ambassadors, encouragement from friends, the characteristics of the brand ambassadors play a significant role in gambling behaviour of the students. The study also, concludes that the casinos, bars, clubs and pubs and local commercial stations among other betting stations, contribute to the likelihood to gamble. Betting even is scaled up by the convenience brought about by the use of gambling website or via Mobile USSD or SMS. The findings indicated that there is a positive and significant moderating effect of legal framework on the effect of frequency of television betting advertisements and brand ambassadors on gambling behaviour. However, there is a negative but insignificant moderating effect of legal framework on the effect of context of betting advertisements on gambling behaviour.

Unique contribution to theory, policy and practice: Therefore, the government needs to ensure that the policies and regulations governing the gambling in Kenya are equitable and just to all market players. The study advocates for the fair taxation on the betting firms in Kenya and do not tax even the consumer on their stakes but only on the profits. This was cited in the findings as one of the major setbacks of the industry.

Keywords ,Effects, brand ambassadors, television, betting advertisements, legal framework, gambling behaviour, undergraduate university students, Kenya. 


\subsection{INTRODUCTION}

Gambling can be considered as the process of playing a game for money by placing bets or playing the odds in the hope of winning. With the shift in the technological platforms of gambling, betting has been made easier and has been able to reach far and wide into developed and developing nations as well. Thus, gambling advertising can be described as the strategies done by casinos, lotteries, bookmakers or other betting companies/organizations to promote and provide the opportunity for an individual to place a bet. It is usually conducted through a variety of media or through sponsorship deals, particularly with sporting events or people (Hing, Cherney, Blaszczynski, Gainsbury \& Lubman, 2014).

Gambling in Africa is a prospering enterprise at the expense of addiction of the participants. According to PricewaterhouseCoopers, South Africa dominates over $90 \%$ of the market share of gambling in sub-Saharan in Africa. According to National Gambling Statistics, in South Africa, Gross Gambling Revenue (GGR) generated in the casino sector represented 66.4\% of the total amount of GGR generated in FY2017 compared to the other legalised gambling sectors (betting on sport and horse racing, LPM \& bingo) (NGB, 2017). Bingo was the fastestgrowing category in 2013 with a $58.9 \%$ increase, followed by LPMs at $25.9 \%$ and sports betting at $21.3 \%$. South Africa's gambling industry has been extrapolated to grow at an average rate of $6.3 \%$ to $\$ 39.1$ billion. This rise and bloom in the gambling business has however, been reproved by Twin Rivers, a South African-based addiction treatment centre which posits that gambling addiction ruins many people's lives especially the young people and is related to different psychological disorders like habit, depression and anxiety (PricewaterhouseCoopers, PwC, 2017).

In Kenya, advertising is categorized as commercial speech and has a constitutional legitimacy under freedom of expression which also guarantees freedom to make public (publicize) events. More importantly too, mass media institutions are protected under the law and rely heavily on advertising as the most reliable means of revenue. Gambling in Kenya is monitored and controlled by the Betting Control and Licensing Board (BCLB) established by an Act of Parliament Chapter 131, Laws of Kenya of 1966. The Board is responsible for regulating betting, lotteries and gaming activities through formulation and issuance of policy guidelines. The Betting, Lotteries and Gaming Act Chapter 131, empowers the Board to license and control premises and the activities carried there in (BCLB, 2018).

With the proliferation and acceptance of gambling in the society, gambling advertisements have become increasingly prominent. It has been observed that this increase in public visibility and availability of gambling has been accompanied by an increase in gambling behaviour and related problems.

\subsection{STATEMENT OF THE PROBLEM}

Evidence of high rates of gambling and associated problems amongst youth indicates that the issue of youth gambling must be addressed to minimise harm (Parke, 2015; Mwadime, 2017). Although most jurisdictions have legislation regulating gambling, the opportunities to put it in check is falling out of hand. The youth are increasingly being exposed to advertisement This publication is licensed under Creative Commons Attribution CC BY. messages from a broad range of media which advocate gambling (Johns, Dale, Alam \& Keating, 2017). According to GeoPoll survey (2017), Kenya has the highest number of young people in sub-Saharan Africa between the ages of 17-35 years who often gamble.

Gambling has been seen to have a serious problem on the current generation young as well as the older people. School absenteeism, drop outs, depression, family break-ups among others have been cited as the issues arising from irresponsible gambling (BCLB, 2018). Due to the adverse financial hiccups that University students always meet, many upon the exposure to the idea of betting quickly immerse themselves into it in hope of making extra cash to cushion their survival in Campuses. They then become too much obsessed and become irresponsible in their betting behaviour due to 'greed' (Mugalo, 2018). In 2017, Betting Control and Licensing Board (BCLB), indicated that gross gambling revenue for the 2016/2017 financial year tremendously grew to $\$ 198 \mathrm{~m}(£ 151 \mathrm{~m})$. However, the allure of instant money comes at a cost of young lives. In 2016, a university student hanged himself after losing on a bet. In addition, more than five suicides and lots of cases of bankruptcy, domestic violence and evictions have been reported. Another study from 2016 estimated that $78 \%$ of university students were problem gamblers. Students misappropriate their school fees while betting in bid to multiply the money (BCLB, 2017). The abuse of drugs and related substances as well as other forms of illicit activities like involvement in prostitution have also been linked to gambling with many students in universities and colleges recording a decline in their academic progress as a result of irresponsible gambling (Mwadime, 2017).

Mwadime (2017), looked into the implications of sports betting in Kenya on the robust growth of the sports betting industry but failed to assess the impact on the gamblers especially the students thus presenting a conceptual gap. Thomas et al. (2018) focused on young people's awareness of the timing and placement of gambling advertising on traditional and social media platforms thus presenting a contextual gap. Mugalo (2018) looked into the impact of habitual betting enterprise on Christian youth in the light of Jesus 'liberating pedagogy but failed to look specifically at the betting advertisements thus presenting a contextual gap. Thus, it is evident that within betting advertisements, there still remains insufficient research to identify some of the behavioural changes that are brought by betting advertisements. Therefore, it is against these backgrounds that the current study sought to establish the effects of television betting advertisements on the gambling behaviour of undergraduate university students aged between 18 and 25 in Kiambu county Kenya.

\subsection{OBJECTIVES}

The general objective of the study is to establish the effect of television betting advertisements on the gambling behaviour of undergraduate university students aged between 18 and 25 years in Kiambu county Kenya. In particular, the paper sought to Establish the effect of brand ambassadors on the gambling bahaviour of undergraduate university students in Kiambu county.

\subsection{THEORETICAL BACKGROUND AND LITERATURE REVIEW}


In this section of the paper, the literature review of the objective informing this paper as well as the theory informing the particular objective were discussed as illustrated below.

\subsection{BRAND AMBASSADORS AND GAMBLING BEHAVIOUR}

Brand ambassadors are the key influencers in the gambling industry that are often used to facilitate and promote their products or brands. They strongly appeal to the general public about the advantages of gambling while at the same time mentioning on the regulatory requirement, and to advocate on shunning away from irresponsible gambling. These ambassadors may include but not limited to, sports icons, media personalities, accomplished celebrities and established business persons (Hing, Lamont, Vitartas \& Fink, 2016).

Since marketing and advertising has a role to play in the adoption of attitudes, beliefs and societal norms, their implication on gambling behaviour has neither been an exception. The intentions of the marketing and advertisements were sought by Parke, Harris, Parke, Rigbye and Blaszczynski (2015) to establish if they were responsible or not. By a critical review on the existing literature on gambling advertising and marketing campaigns the study concluded that marketing and advertising in gambling needs to facilitate more informed choice for consumers, and a more balanced approach in the framing of gambling. The influencers incorporated in the marketing campaigns need to propagate positive and constructive message to the public. It was suggested that risk information is presented asynchronously to gambling promotions, as opposed to being delivered as peripheral information, and moreover future strategies need to be based on robust empirical evidence demonstrating the impact of responsible gambling advertising and marketing on behaviour.

Gordon and Chapman (2014) likewise analysed the brand community and sports betting in Australia by use of a content analysis and an exploratory approach. The findings suggested that sports betting marketing appears to be heavily embedded within community cultures surrounding sport which mostly uses coded gambling language. Thus, for the consumers to be able to identify the type of betting ad odds attached to them, brand ambassadors stepped in to offer education and knowledge about the right ways to bet. This ensured that the participants were aware of, and engaged by, such sports betting brand community activities. The gambling marketing was concluded to have a pivotal role in socialising consumers to sports betting.

\subsection{SOCIAL LEARNING THEORY}

Albert Bandura (1977) developed this theory. The theory conforms with behaviorist learning theories such as operant conditioning and classical conditioning. Further, he added two more ideas: the environment shapes an individual's behavior This publication is licensed under Creative Commons Attribution CC BY. through learning by observation and the process of mediation occurs between a stimulus and a response. Individuals that are observed are called model.

Social Learning Theory states that patterns can be learned by experiencing phenomena directly or by observing others' experiences. These experiences often occur from the environment through the process of observational learning, i.e., between stimuli $\&$ responses. The adverts act as triggers for those who haven't started to bet. In relation to this study, this influence could be from the media in form of television advertisements. Gambling individuals get themselves into this through direct experience whereby they watch the adverts then access the betting cites directly from their phones and the impact it has to their lives now becomes in a direct way. Others may learn to gamble by learning the behaviour from other people either through observation or even getting to hear their experience in betting either through the win they get or the loses they experience. Thus, this theory is relevant to this study as it informs how brand ambassadors could influence the gambling behaviour of undergraduate university students in Kiambu county Kenya.

\subsection{METHODOLOGY}

This study applied a descriptive research design. The study targeted the Public Chartered Universities that are in Kiambu County. The respondents were the undergraduate students from the School of Communications \& Development Studies (SCDS) and the school of business (students between 18 and 25 years of age, those who have mobile betting accounts and those who have gambled at least once in the past 12 months to be eligible to participate in this research). The study adopted a stratified random sampling technique to select the sample size. Since the population is indefinite, that is, more than 10000 students, the study considered a sample frame of equal number of students across the 4 strata. Thus, the sample frame included 384 students from the universities. The study used questionnaires to collect the data from the target respondents. Analysis was done by use of SPSS software (v22.0).

The findings indicated that there is a high probability of responsible gambling behaviour (by 2.309, 1.370 and 1.008 times) for those students who place were motivated by the brand ambassadors' affiliations, economic status and media personalities respectively compared to those who are motivated by their accomplishment level. The relationship found out that the null hypothesis stands with a chi square value of 7.070 and a $p$ value of 0.070 .

The findings likewise, indicate that there is a high probability of responsible gambling behaviour (by 2.129 times) for those students who agreed that they get motivated to bet by brand ambassadors compared to those who are not. The relationship was found to be statistically significant a chi square value of $3.534 \mathrm{a}$ and a $\mathrm{p}$ value of 0.05 . The findings, indicate that there is a high probability of responsible gambling behaviour (by 0.232 times) for those students who were in agreement with the brand ambassadors' influence and their interest in gambling compared to those who did not agree with the brand ambassadors' influence and their interest in gambling. The relationship was found to be 
statistically significant a chi square value of 10.174 and a $p$ value of 0.001 .

The findings likewise, indicate that there is a high probability of responsible gambling behaviour (by 4.450 times) for those students who allow your friends to decide on what bet to place compared to those who do not allow your friends to decide on what bet to place. The relationship was found to be statistically significant a chi square value of 10.174 and a $\mathrm{p}$ value of 0.001 . These findings are in tandem with Deans et al (2017) who indicated that the gamblers also described that the inducements offered by the industry were effective marketing strategies in getting themselves and other young men to bet on sports. Inducements were also linked with feelings of greater control over betting outcomes and stimulated some individuals to sign up with more than one betting provider. Legislators were encouraged to consider the cultural lag between an evolving gambling landscape, which supports sophisticated marketing strategies, and effective policies and practices which aim to reduce and prevent gambling harm.

\subsection{CONCLUSION}

The research came up with the following conclusions in line with the subject of study.

This study has demonstrated that the gambling behaviour of undergraduate university students aged between 18 and 25 in Kiambu county Kenya is influenced by the television betting advertisements on the gambling behaviour of undergraduate university students. This has been shown by the students gambling behaviour which is validated by the number of bets they place.

Interest in a certain personality of a brand ambassador increases the chances of one placing a bet. Likewise, encouragement from friends, the characteristics of the brand ambassadors increases the chances of students engaging in gambling. However, given the use of personal funding and many of the students relying on the act for livelihood, there is a likelihood of irresponsibility while placing the bets.

The gambling bahaviour of these students can thus be concluded to be fairly responsible however, students do not use their leisure money as stakes to place the bets. Despite them placing one game per bet and checking the bet odds before betting a significant half of the students stake their bets using personal funding, this indicative of irresponsible gambling bahaviour.

\subsection{RECOMMENDATIONS}

The study recommends the following:

1. The government needs to ensure that the policies and regulations governing the gambling in Kenya are equitable and just to all market players.
2. The BCLB needs to scale up awareness to spread the information about responsible gambling among students as well as all Kenyans.

3. The study advocates for the fair taxation on the betting firms in Kenya and do not tax even the consumer on their stakes but only on the profits. This was cited in the findings as one of the major setbacks of the industry.

\section{REFERENCES}

Bandura, A. (1971). Social learning theory. New York City. JSTOR. 1(1973), pp. 34-57. Sekaran, U., \& Bougie, R. (2019). Research methods for business: A skill building approach. john wiley \& sons.

BCLB. (2018). Betting Control and Licensing Board Available At: http://www.interior.go.ke/index.php/2015-03-02-08$\underline{39-13}$

Deans, E. G., Thomas, S. L., Derevensky, J., \& Daube, M. (2017). The influence of marketing on the sports betting attitudes and consumption behaviours of young men: implications for harm reduction and prevention strategies. Harm reduction journal, 14(1), 1 - 12

Gordon, R., Gurrieri, L., \& Chapman, M. (2015). Broadening an understanding of problem gambling: The lifestyle consumption community of sports betting. Journal of Business Research, 68(10), 2164-2172.

Hing, N., Cherney, L., Blaszczynski, A., Gainsbury, S. M., \& Lubman, D. I. (2014). Do advertising and promotions for online gambling increase gambling consumption? An exploratory study. International Gambling Studies, 14(3), 394-409.

Johns, R., Dale, N., Alam, S. L., \& Keating, B. (2017). Impact of gambling warning messages on advertising perceptions. Melbourne: available at: https://responsiblegambling.vic.gov.au/documents/62/R esearch-report-impact-of-gambling-warning-messageson-advertising-perceptions.pdf 
Mugalo, J. K. (2018). Impact of Habitual Betting Enterprise on

Christian Youth in The Light of Jesus'liberating

Pedagogy: A Case of Soweto Village, Nairobi County,

Kenya. (Doctoral dissertation, University of Nairobi).

Mwadime, A. (2017). Implications of Sports Betting in Kenya:

Impact of Robust Growth of the Sports Betting Industry

(Doctoral dissertation, United States International

University-Africa).

Parke, A., Harris, A., Parke, J., Rigbye, J., \& Blaszczynski, A. (2015). Responsible marketing and advertising in gambling: A critical review. The journal of gambling business and economics, 8(3), 21-35.

PricewaterhouseCoopers, PwC, (2017). Gambling outlook for South Africa 2017-2021. Retrieved from: https://www.pwc.co.za/en/assets/pdf/gambling-outlook-

2017-2021.pdf

Thomas, S. L., Bestman, A., Pitt, H., Cassidy, R., McCarthy, S., Nyemcsok, C., ... \& Daube, M. (2018). Young people's awareness of the timing and placement of gambling advertising on traditional and social media platforms: a study of 11-16-year-olds in Australia. Harm reduction journal, 15(1), 51.

\section{AUTHORS}

First Author - Juliet Mwai, Masters Degree Candidate at Jomo Kenyatta University of Agriculture and Technology, Kenya

Co-Author - Professor Hellen K. Mberia is a Lecturer at the School of Communication and Development Studies at Jomo Kenyatta University of Agriculture and Technology, Kenya 